\title{
A Study on Generation Time of Sensitive and Resistant Mycobacterium tuberculosis Isolates
}

\author{
Tapajyoti Mukherjee ${ }^{1}$, Avranil Goswami², Urmita Chakraborty³, Monalisa Majumdar4, Sukanta Sinha5 \\ Nishith Kumar Pal ${ }^{6}$ \\ ${ }^{1}$ Assistant Professor, Department of Microbiology, Burdwan Medical College, Purba Bardhaman, \\ West Bengal, India. \\ 2Microbiologist, SNCU, Department of Paediatric Medicine, Medical College, Kolkata, \\ West Bengal, India. \\ ${ }^{3}$ Research Associate, Department of Virology, Dr. Anjali Chatterjee Regional Research Institute for Homeopathy, CCRH, Kolkata, \\ West Bengal, India. \\ ${ }^{4}$ Professor and HOD, Department of Microbiology, Burdwan Medical College, Purba Bardhaman, \\ West Bengal, India. \\ 5Professor and HOD, Department of Microbiology, Mizoram Institute of Medical Education and Research, Falkawn, \\ Mizoram, India. \\ ${ }^{6}$ Professor and HOD, Department of Microbiology, Jagannath Gupta Institute of Medical Sciences and Hospital, Budge Budge, \\ West Bengal, India.
}

\section{ABSTRACT}

\section{BACKGROUND}

Low occurrence of mutant strains of Mycobacterium tuberculosis with multi-drug resistant genes in cavitary pulmonary tuberculosis and dramatic reduction of metabolic activity of tubercle bacilli in chronically infected animals reveal that apart from drug resistant genes, long generation time could be an additional explanation of drug resistance. We wanted to analyze the drug resistance pattern of Mycobacterium tuberculosis isolates from new sputum smear positive patients and previously treated patients on failing regimen in the light of generation time.

\section{METHODS}

20 new sputum smear positive pulmonary tuberculosis patients and 20 previously treated patients on failing regimen were placed in the study. Mycobacterium tuberculosis isolates were obtained in pure culture by decontaminating, liquefying \& concentrating sputum sample \& anti-tubercular susceptibility tests were performed. From these, 10 all-drug (Rifampicin and Isoniazid) sensitive isolates, 10 resistant to at least one drug (Rifampicin/Isoniazid) were chosen. Single mycobacterial cell suspension was prepared from each. After proper standardization, they were inoculated in Middlebrook $7 \mathrm{H} 9$ broth and incubated at $37^{\circ} \mathrm{C}$ in $10 \% \mathrm{CO}_{2}$. Subculture was done at intervals of $0,18,36,54,72$ hours, using $10 \mu$ l of each culture suspension in Middlebrook 7H11 agar plate to measure $\mathrm{CFU} / \mathrm{ml}$. Generation time was evaluated from steep portion of the growth curve using standard formula.

\section{RESULTS}

It was found that, mean generation time of MDR isolates of previously treated patients on failing regimen $(35.27 \pm 2.44 \mathrm{hrs}$.) were significantly greater $(\mathrm{p}=0.04$, i.e. $<0.05)$ in comparison to the drug sensitive isolates $(21.42 \pm 1.6 \mathrm{hrs}$. $)$.

\section{CONCLUSIONS}

Thus, mutant strains of tubercle bacilli, which are slow multipliers, as suggested by their long generation time could hardly be killed by the regimens containing drugs targeting bacterial multiplication. Hence, apart from genes, long generation time is a potential, additional explanation for drug resistance.

\section{KEY WORDS}

M. tuberculosis, Generation Time, MDR, M. fortuitum
Corresponding Author: Dr. Tapajyoti Mukherjee, Assistant Professor, Department of Microbiology, Burdwan Medial College, Purba Bardhaman, West Bengal, India. E-mail: tmukherjee2008@gmail.com

DOI: 10.14260/jemds/2019/542

Financial or Other Competing Interests: None.

How to Cite This Article:

Mukherjee T, Goswami A, Chakraborty U, et al. A study on generation time of sensitive and resistant Mycobacterium tuberculosis isolates. Evolution Med. Dent. Sci. 2019;8(31):2489-2494, DOI: $10.14260 / \mathrm{jemds} / 2019 / 542$

Submission 06-06-2019, Peer Review 16-07-2019, Acceptance 22-07-2019, Published 05-08-2019.

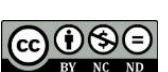




\section{BACKGROUND}

Tuberculosis, an infectious disease caused by Mycobacterium tuberculosis and rarely by other organisms of the tuberculosis complex, has been scourge of mankind for thousands of years, not only as a medical malady but also as a social and economic tragedy and remains one of the deadliest diseases of the world today. Globally, in 2017, there were estimated 10 million incident cases of TB with 1.3 million deaths among Human Immunodeficiency Virus (HIV) negative cases and in India 2.74 million estimated incident cases and 4.1 lakhs (excluding HIV) deaths occurred in 2017. ${ }^{1}$ Since Dr. Robert Koch isolated the dreaded organism at the end of nineteenth century a number of potential anti- tubercular drugs (ATDs) came into existence giving curative treatment for TB a reality. Initial euphoria of ability to cure TB led to indiscriminate use of ATDs paved the way for emergence of drug-resistant strains particularly multidrug resistant TB (MDR-TB), which has become significant public health problem worldwide. There are so many reasons for treatment failure out of which mutant strains with resistant genes is most significant. However, literature review suggests that overall probability of spontaneous mutations causing resistance to both Isoniazid (INH) and Rifampicin (RIF) would be in 1 in $10^{14}$ replications, whereas tubercular cavity usually contains $10^{7}$ to $10^{9}$ bacilli. $^{2}$ Hence the chance of the development of spontaneous dual resistance to Rifampicin and Isoniazid i.e. MDR-TB, in cavitary pulmonary tuberculosis is expected to be extremely low. ${ }^{2}$ It is also evident that although effective bactericidal drugs are available, still treatment of TB, requires a remarkably long course of therapy to achieve therapeutic cure. ${ }^{3}$ Moreover, it has also been recorded that $M$. tuberculosis dramatically reduces both its growth and metabolic activity in chronically infected animals, doubling only once every $100 \mathrm{~h}$ or more.4,5 Even, some drug resistant isolates of Mycobacterium tuberculosis had very slow rate of growth ${ }^{6}$ and few strains with INH resistance, without any resistant gene, had significantly higher (up to $67.9 \mathrm{hrs}$.) generation time ( 0 'Sullivan et $\mathrm{al}^{7}$ ). Waddell et $\mathrm{al}^{8}$ (2009) also reported that large proportion of bacilli in cavitating lung lesions are either slow growing or unresponsive to INH therapy as diminished transcriptional response leads to drug tolerance. Therefore, it seems the hypothesis of propagation of mutants having long generation time might be an additional explanation which leads to treatment failure. The present investigation is aimed at exploring this hypothesis.

\section{METHODS}

A cross-sectional observational study was conducted in a tertiary care hospital of eastern India. Permission was obtained from the Institutional Ethics Committee before conduction of this study. Written informed consent was obtained from all participants. However, the sputum samples were anonymized. In this study, consecutive 20 new pulmonary tuberculosis (PTB) cases having sputum smear positive for acid fast bacilli (AFB) \& 20 previously treated patients on failing regimen (who remained sputum positive after four months of treatment) of all age groups and sexes, giving informed consent and having no co-morbid illness were recruited. Moreover, reference strains of Mycobacterium tuberculosis, H37Rv and H37Ra were included in this study. Patients with diabetes mellitus, pregnancy, malignancy, HIV infection, patients on immuno-suppressive agents and transplant recipients were excluded from the study group. After collection of spot and early morning sputum samples, ${ }^{9}$ liquefaction, decontamination and concentration of those samples were done following the procedure of $\mathrm{N}$-acetyl $\mathrm{L}$ cysteine - sodium hydroxide method using Lyfectol kit (Microxpress, 20301012). Identification of the Mycobacterium tuberculosis from the sputum samples was done by sputum smear microscopy after staining by Ziehl-Neelsen method,10,11 colony morphology on Lowenstein-Jensen agar slope $11,12,13$ and relevant biochemical tests. 12 Then, anti-tubercular susceptibility tests were performed by standard economic variant of $1 \%$ Proportion method. ${ }^{14}$ From these isolates, 10 alldrug (RIF + INH) sensitive isolates, 10 resistant to at least one drug (RIF, INH) were chosen and from each isolate, single mycobacterial cell suspension was prepared in Middlebrook 7H9 broth by filtering through a $5 \mu \mathrm{m}$ syringe filter. ${ }^{15}$ After proper quantification of mycobacteria by Petroff hausser chamber ${ }^{15}$, working dilutions were prepared containing $10^{5}$ bacteria per $\mathrm{ml}$. Then, these were incubated in the dark at $37^{\circ} \mathrm{C}$ inside CO2 incubator (Heal Force, Shanghai, China) with 5$10 \%$ CO2 and high humidity and agitated daily and $10 \mu \mathrm{l}$ of each culture suspension was inoculated in Middlebrook 7H11 agar plate to measure $\mathrm{CFU} / \mathrm{ml}$ at different time-points (Hour $0,18,36,54,72$ ). Same experiments were done with reference strains of Mycobacterium tuberculosis, H37Rv and H37Ra, alongside the experiments with isolates from patients.

Generation time $(\mathrm{g})$ was evaluated from graph (steep portion of growth curve) of the above colony counts using standard formula where $\mathrm{N}_{1}$ and $\mathrm{N}_{2}$ are the population number $(\mathrm{CFU} / \mathrm{ml})$ at time $\mathrm{t}_{1}$ and $\mathrm{t}_{2}$ respectively. ${ }^{16,17}$

$$
g=\frac{0.301\left(t_{2}-t_{1}\right)}{-\log _{10} N_{2}-\log _{10} N_{1}}
$$

\section{Statistical Analysis}

The experiment was performed in triplicate and average value was taken. Statistical analysis was performed by Student's- $t$ test using GraphPad Prism version 5.00 for Windows with a $\mathrm{p}$ value of 0.05 .

\section{RESULTS}

In the present study, a total of twenty (20) isolates from new sputum smear positive (for AFB) patients were included and out of that, 19 (95\%) were Mycobacterium tuberculosis isolates and $1(5 \%)$ was MOTT. But, all of the twenty (20) isolates from previously treated patients on failing regimen were found to be Mycobacterium tuberculosis isolates. Among 19 (95\%) Mycobacterium tuberculosis isolates from new sputum smear positive patients, 18 (94.7\%) were sensitive to both RIF and INH and $1(5.3 \%)$ was resistant to INH only. Moreover, of all the twenty (20) Mycobacterium tuberculosis isolates from previously treated patients on failing regimen, 18 (90\%) isolates were resistant to both RIF and INH i.e. MDR isolates 
and $2(10 \%)$ were resistant to INH only. However, no isolate was found to be resistant to RIF (only) or sensitive to both of the drugs. (Table 1).
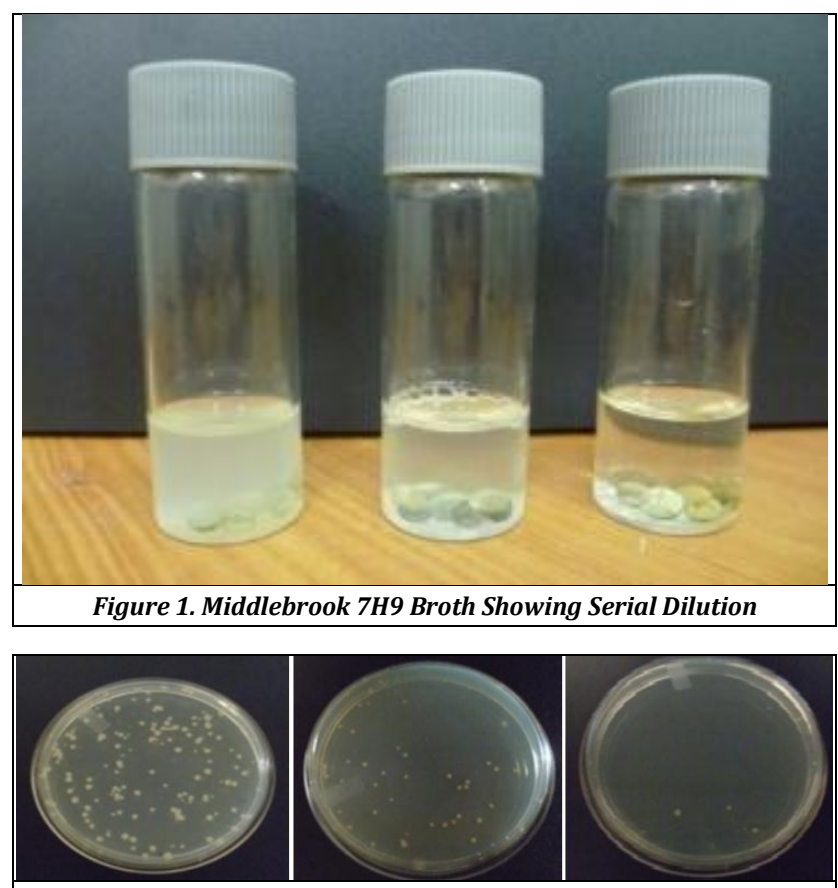

Figure 2. Middlebrook 7H11 Agar Showing CFU from Serial Dilutions

\begin{tabular}{|c|c|c|c|}
\hline $\begin{array}{l}\text { Drug Resistance } \\
\text { Pattern }\end{array}$ & \multicolumn{2}{|c|}{$\begin{array}{l}\text { New Sputum } \\
\text { Smear Positive } \\
\text { (19) No. (\%) }\end{array}$} & $\begin{array}{l}\text { Previously Treated } \\
\text { Patients on Failing } \\
\text { Regimen (20) No. (\%) }\end{array}$ \\
\hline Sensitive to both & \multicolumn{2}{|l|}{$18(94.7 \%)$} & 0 \\
\hline Monoresistance to Rifampicin & \multicolumn{2}{|l|}{0} & 0 \\
\hline \begin{tabular}{|l|} 
Monoresistance to Isoniazid \\
\end{tabular} & \multicolumn{2}{|l|}{$1(5.3 \%)$} & $2(10 \%)$ \\
\hline Resistance to both & \multicolumn{2}{|l|}{0} & $18(90 \%)$ \\
\hline \multicolumn{4}{|c|}{$\begin{array}{c}\text { Table 1. Distribution of Drug Resistance Pattern of Mycobacterium } \\
\text { tuberculosis Isolates from New Sputum Smear Positive }(N)(n=19) \& \\
\text { Previously Treated Patients on Failing Regimen }(F)(n=20)\end{array}$} \\
\hline \multicolumn{2}{|l|}{ Isolates } & & $\begin{array}{l}\text { an Generation Time in } \\
\text { Hours (Mean + SD) }\end{array}$ \\
\hline \multicolumn{2}{|c|}{ Drug sensitive isolates } & & $21.42 \pm 1.6$ \\
\hline \multicolumn{2}{|c|}{ Drug resistant isolates } & & $30.72 \pm 2.04$ \\
\hline \multicolumn{2}{|c|}{ INH-R isolate from new cases } & & $18.95+1.58$ \\
\hline \multicolumn{2}{|c|}{ INH-R isolates from previously treated cases } & & $20.69+1.02$ \\
\hline \multicolumn{2}{|c|}{ MDR isolates from previously treated cases } & & $35.27 \pm 2.44$ \\
\hline \multicolumn{4}{|c|}{$\begin{array}{l}\text { Table 2. Comparison of Mean Generation Times (hrs.) of } \\
\text { Drug Sensitive \& Resistant Isolates }\end{array}$} \\
\hline
\end{tabular}

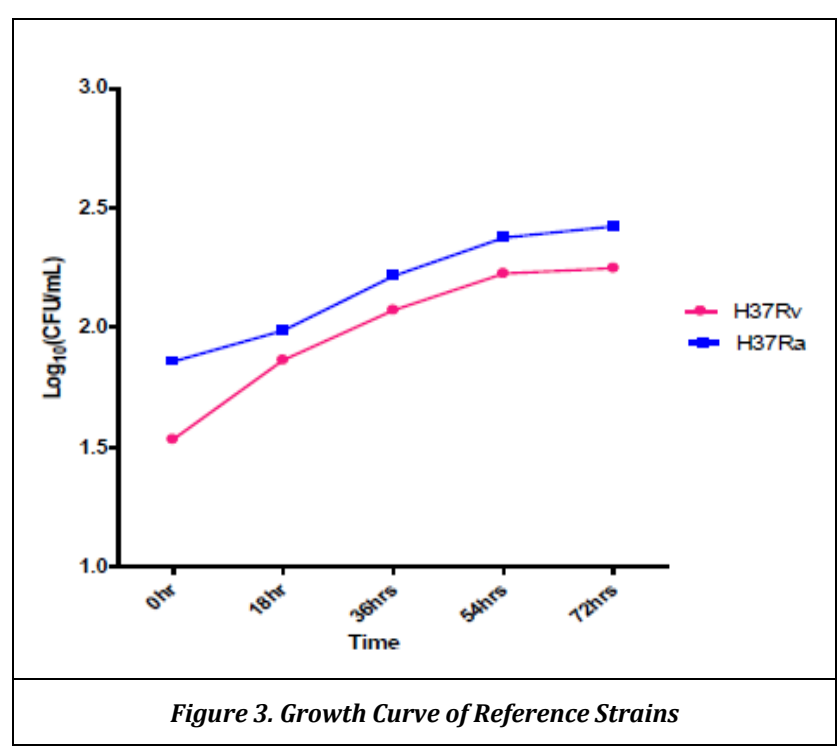

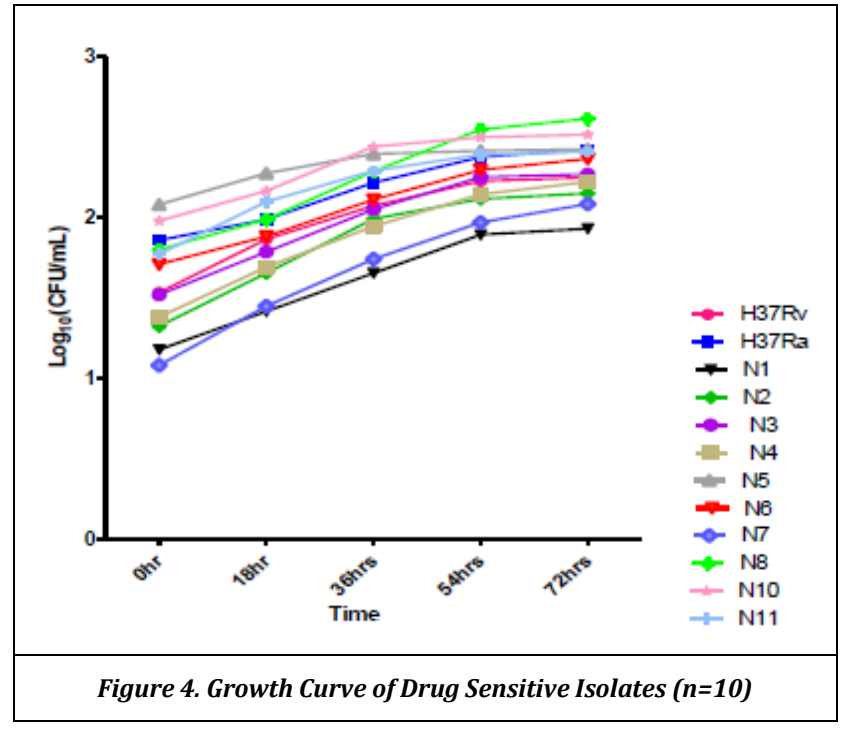
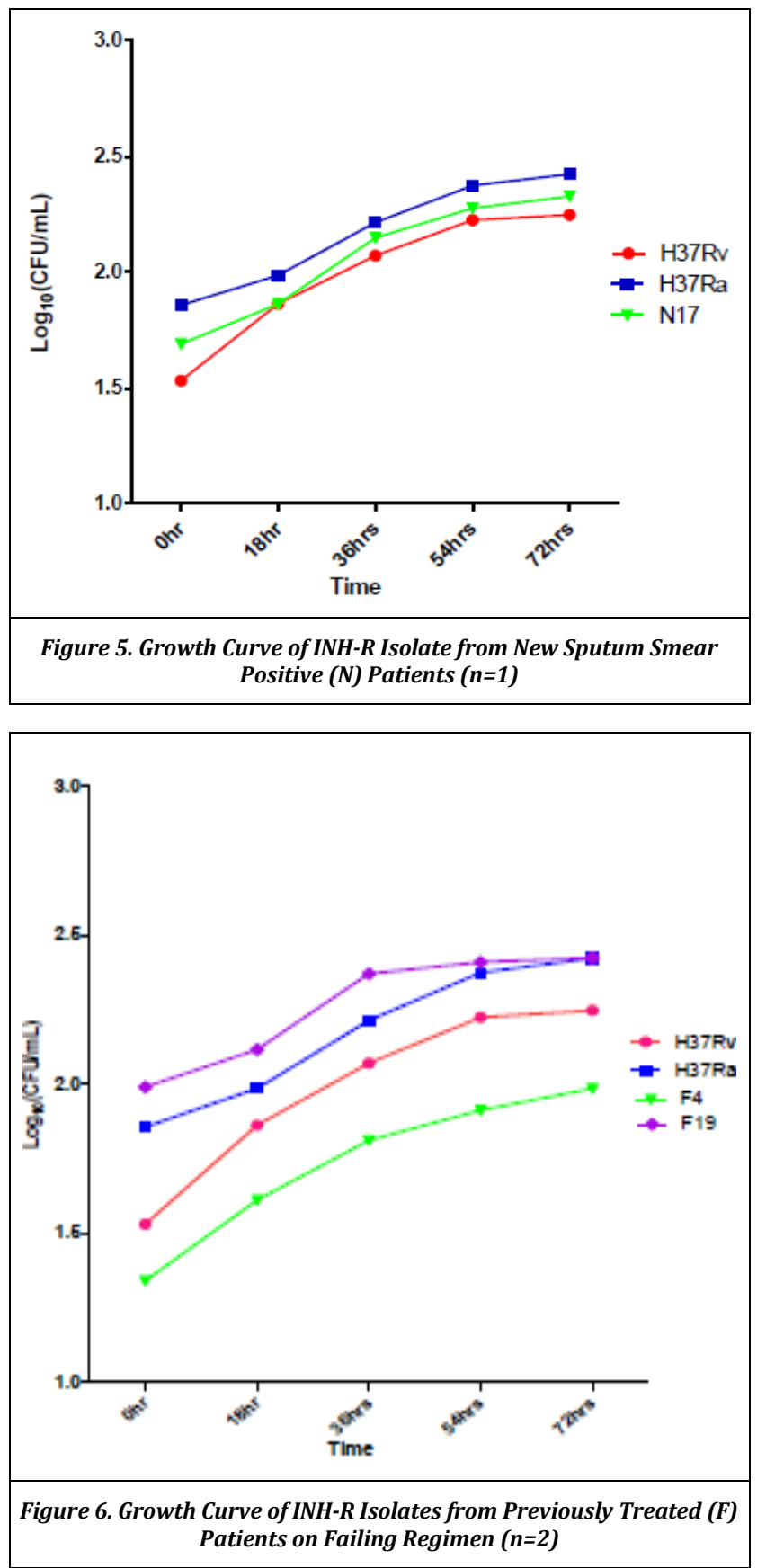

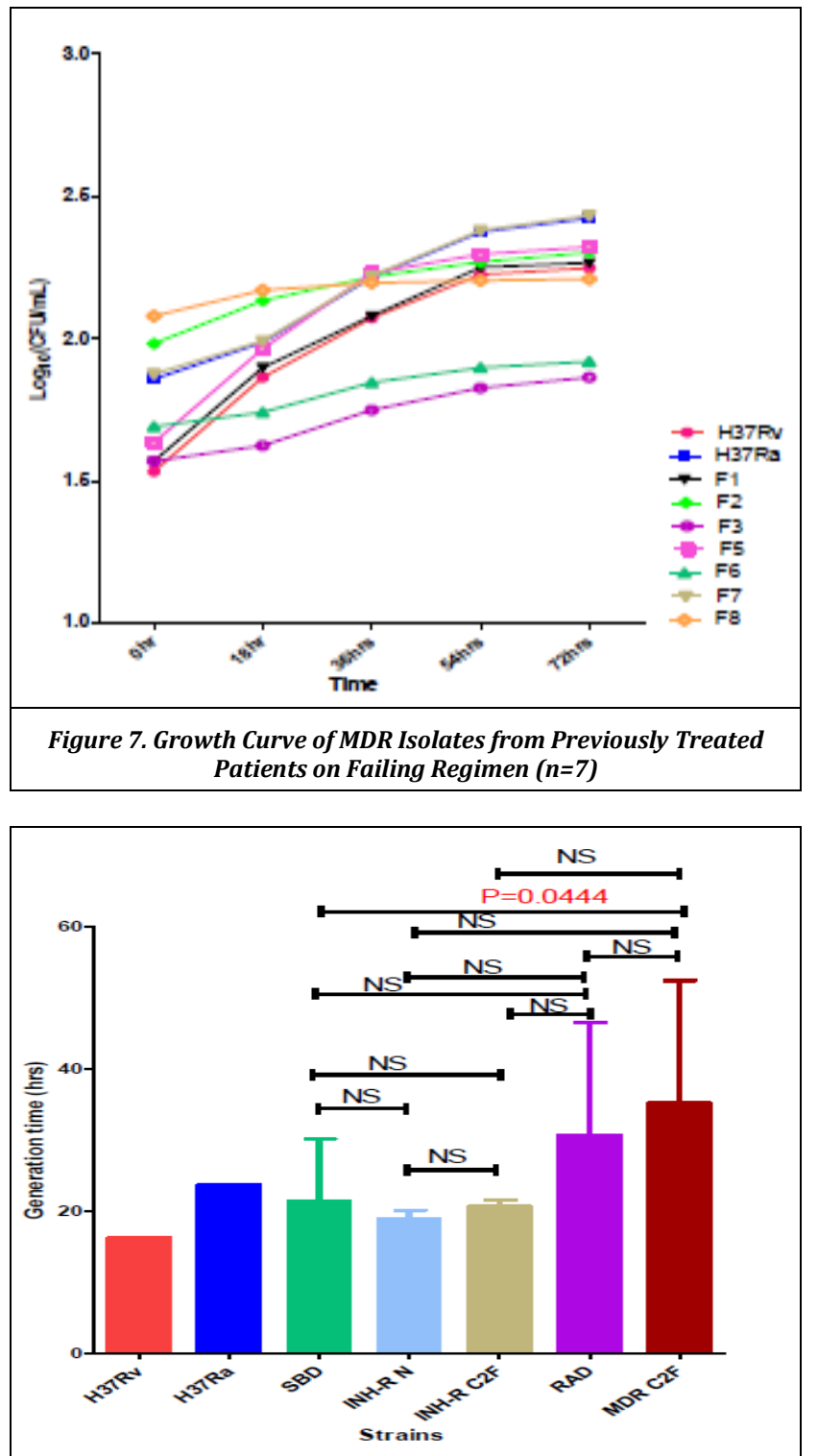

Figure 8. Comparison of Mean Generation Time of Isolates Sensitive to Both Drugs (SBD), INH-R Isolate from New Cases (INH-R N) and Previously Treated Patients on Failing Regimen (INH-R C2F), Isolates Resistant to At Least One Drug (RAD) \& MDR Isolates from Previously Treated Patients on Failing Regimen (MDR C2F) with H37Rv \& H37Ra

The mean generation time of reference strains were found to be $16.33 \mathrm{hrs}$ for H37Rv and $23.76 \mathrm{hrs}$ for H37Ra by serial CFU count and using the standard formula. The experiment was performed in triplicate and mean value was taken. (Figure 3 ). Likewise, the mean generation times of ten (10) all drug sensitive isolates from new sputum smear positive patients are shown below in Figure 4. The experiment in each case was performed in triplicate and mean value was taken.

Similarly, the calculation of mean generation times of ten (10) drug resistant isolates including one (1) INH resistant new case isolate, two (2) INH resistant and seven (7) multidrug resistant isolates from previously treated patients on failing regimen are shown above in Figure 5-7. The experiment in each case was performed in triplicate and mean value was taken. The mean of mean generation time calculated for ten (10) isolates sensitive to both of the drugs and ten (10) isolates resistant to at least one drug were $21.42 \pm 1.6 \mathrm{hrs}$. and $30.72 \pm 2.04 \mathrm{hrs}$. respectively. Moreover, the generation time of only INH resistant Mycobacterium tuberculosis isolate from new sputum smear positive patients was $18.95 \pm 1.58 \mathrm{hrs}$. whereas mean of mean generation times of two (2) INH resistant Mycobacterium tuberculosis isolates and seven (7) MDR isolates from previously treated patients on failing regimen were $20.69 \pm 1.02 \mathrm{hrs}$. and $35.27 \pm 2.44 \mathrm{hrs}$. respectively. This result is shown here in Table 2 and Figure 8 which shows that mean generation time of the MDR isolates of previously treated patients were significantly greater $(\mathrm{p}=$ 0.0444 , i.e. $<0.05$ ) in comparison to drug sensitive isolates.

\section{DISCUSSION}

In this study, most of the isolates of new sputum smear positive patients were Mycobacterium tuberculosis and only $5 \%$ were the $M$. fortuitum. It has been seen that in Indian studies, Mycobacterium tuberculosis has always been found as the major cause of mycobacterial infections and the proportion of NTM has varied from less than one to $28 \% .{ }^{18}$ Species like Mycobacterium fortuitum, Mycobacterium avium, Mycobacterium chelonae etc. have been isolated in different studies. Out of all the specimens from patients with suspected tuberculosis, Shanker et al, ${ }^{19}$ Chakrabarty et al, ${ }^{20}$ Jesudason et $\mathrm{al}^{21}$ reported Mycobacterium tuberculosis as the commonest isolate i.e. $92.1 \%, 92 \%, 96 \%$ respectively which is at par with our observation i.e. 95\%, though it differs from Karak et al 22 (82.6\%). According to Simons et al, ${ }^{23} \mathrm{M}$. fortuitum stands out as the commonest isolate (40\%) of pulmonary NTM disease in Indian studies followed by M. kansasii (33\%) which supports the finding of Chakrabarty et $\mathrm{al}^{20}$ i.e. they noticed $2.8 \%$ of the total isolates were $M$. fortuitum..$^{20,23}$ Moreover, in India with standardized drug regimens used by RNTCP the treatment failure cases of Category-I and Category-II cases are $2 \%$ and $6 \%$ respectively. ${ }^{24}$ The prevalence of MDR-TB, defined as resistance to INH and RIF with or without resistance to other drugs is $2 \%$ to $3.5 \%$ in new cases and around $10 \%$ to $13 \%$ in previously treated cases ${ }^{1}$ and overall emergence of resistance to RIF is only $2 \%$ of patients despite a high level $(18 \%)$ of initial resistance to INH, either alone or in combination with other anti-tubercular drugs. ${ }^{24}$ But, the incidence of monoresistance to INH among new sputum smear positive patients as recorded by researchers like, Ramachandran et al ${ }^{25}$ (TRC, Chennai), Santha et al ${ }^{26}$ were $5.4 \%, 5.3 \%$, that simulates our observation i.e. 5.3\% although it is varied widely from the figure of Paramasivan et al ${ }^{27}$ i.e. $12.8 \%$. It is evident from others report that, RIF resistant and MDR strains are rarer observations particularly among new sputum smear positive cases. In this study, no such strain could be detected possibly due to small sample size as principal objective of it was to find relationship between drug resistance and generation time. Literature review shows paucity of reports regarding the resistance pattern of isolates from previously treated patients on failing regimen. Still, incidence of MDR-TB was $87 \%$, as reported by Rahaman et $\mathrm{al}^{28}$ and this is supported by this study (90\%). But, Jain et $\mathrm{al}^{29}$ and Osman et al ${ }^{30}$ recorded $77.02 \%$, $56.1 \%$ respectively. Moreover, Jain et al ${ }^{29}$ observed $7.43 \%$ \& $2.02 \%$ of previously treated patients on failing regimen were monoresistant to INH \& RIF respectively which is very close to our figures i.e. $10 \%$ and nil. It is also note-worthy that the generation time of reference strains like H37Rv, obtained from our study, (i.e. $16.33 \mathrm{hrs}$.) simulates the data obtained by O'Sullivan et $\mathrm{al}^{7}$ (15.9 hrs.). It was seen that, the monoresistant 
isolates both from new cases (Only one isolate having generation time of $18.95 \mathrm{hrs}$.) and previously treated cases on failing regimen (mean generation time of two isolates was $20.69 \mathrm{hrs}$.), were not found to have statistically significant slower generation time than the sensitive isolates (Mean generation time of ten isolates was $21.42 \mathrm{hrs}$.). Perhaps, scanty number of monoresistant isolates could be attributed for this. But, it was noted that mean generation time calculated from seven clinical MDR isolates (35.27 hrs.) was significantly higher $(p=0.0444$, i.e. $<0.05)$ than that of drug sensitive isolates supporting the observations of O'Sullivans'. This observation led us to think that, apart from drug resistant genes involved behind the treatment failure cases, there are problems like dormant bacilli with longer generation time that could hardly be killed by drugs principally targeting bacterial multiplication.

\section{CONCLUSIONS}

Thus, we observed that mean generation time of drug sensitive isolates was significantly less $(p=0.0444$, i.e. $<0.05)$ in comparison to the MDR isolates of previously treated patients on failing regimen. This indicates that mutant strains of tubercle bacilli, which are slow multipliers, as suggested by their long generation time, could hardly be killed by the regimens containing drugs targeting bacterial multiplication and long generation time is a potential, additional explanation of the treatment failure cases. M. tuberculosis lives in a complex environment within the human host where numerous adaptive pressures are applied, of which antibiotic selection is but one. So, evaluation of generation time as a contributing factor in treatment failure cases in particular could not solely explain full range of factors influencing fitness of the isolate in the adaptive landscape. However, it may be concluded that isolates which are hardly multiplying may not be killed by standard regimen consisting of bactericidal drugs leading to undue consumption of costly and hazardous second line antitubercular drugs for a considerable period of time. Further studies with larger samples to analyse the drug resistant $M$. tuberculosis genotypes in the light of generation time particularly in vivo setting, producing statistically more significant data will enrich our knowledge in understanding the gloomy picture of treatment failure cases of TB and could open new avenue in tuberculosis treatment research.

\section{ACKNOWLEDGEMENT}

I express my heartfelt thanks and gratitude to, I.P.G.M.E.R. \& S.S.K.M. Hospital for allowing me to conduct the study.

\section{REFERENCES}

[1] Global tuberculosis report 2018. Geneva: World Health Organization, 2018. Licence: CC BY-NC-SA 3.0 IGO. 265 p. Report No.: WHO/CDS/TB/2018.20.

[2] Banerjee S, Siddiqi N, Hasnain SE. Drug-Resistant Tuberculosis. In: Sharma SK, Mohan A, eds. Tuberculosis. $2^{\text {nd }}$ edn. New Delhi, India: Jaypee Brothers Medical Publishers (P) Ltd., 2009: p. 685.

[3] Salomon JA, Lloyd-Smith JO, Getz WM, et al. Prospects for advancing tuberculosis control efforts through novel therapies. PLoS Med 2006;3(8):e273.

[4] Gill WP, Harik NS, Whiddon MR, et al. A replication clock for Mycobacterium tuberculosis. Nat Med 2009;15(2):211-4.

[5] Munoz-Elias EJ, Timm J, Botha T, et al. Replication dynamics of Mycobacterium tuberculosis in chronically infected mice. Infect Immun 2005;73(1):546-51.

[6] Von Groll A, Martin A, Portaels F, et al. Growth kinetics of Mycobacterium tuberculosis measured by quantitative resazurin reduction assay: a tool for fitness studies. Braz J Microbiol 2010;41(2):300-3.

[7] O'Sullivan DM, McHugh TD, Gillespie SH. Mapping the fitness of Mycobacterium tuberculosis strains: a complex picture. J Med Microbiol 2010;59(Pt 12):1533-5.

[8] Waddell SJ, Tudo G, Garton NJ, et al. RNA profiling of Mycobacterium tuberculosis from patient samples and in vitro models informs and revises drug development strategies. Spring Meeting Harrogate 30 March - 2 April, 2009.

[9] Watt B, Rayner A, Harris G. Mycobacterium. In: Collee JG, Fraser AG, Marmion BP, et al. eds. Mackie \& McCartney Practical Medical Microbiology. 14th edn. Washington, DC, USA: Churchill Livingstone 2008: p. 329-42.

[10] Central TB Division, Directorate General of Health Services, Ministry of Health \& Family Welfare, Revised National Tuberculosis Control Programme, Training Course for Program Manager. Developed under GOI-WHO collaboration programme (2008-2009). Modules 2. 2011:22,30-9.

[11] Forbes BA, Sahm DF, Weissfeld AS, et al. Mycobacterium. In: Forbes BA, Sahm DF, Weissfeld AS, eds. Bailey \& Scott's diagnostic microbiology. $12^{\text {th }}$ edn. Philadelphia, PA, USA: Mosby Elsevier 2007: p. 489-94.

[12] Della-Latta P. Mycobacteriology and anti-mycobacterial susceptibility testing. In: Isenberg HD, Garcia LS, eds. Clinical microbiology procedures handbook. $2^{\text {nd }}$ edn. Washington, DC, USA: ASM Press 2007;2.

[13] Bhatia R. The Mycobacteria. In: Sharma SK, Mohan A, eds. Tuberculosis. $2^{\text {nd }}$ edn. New Delhi, India: Jaypee Brothers Medical Publishers (P) Ltd., 2009: p. 103-4.

[14] Central TB Division, Directorate General of Health Services, Ministry of Health \& Family Welfare, Revised National Tuberculosis Control Programme, Manual of Standard Operating Procedures (SOPs) Culture of Mycobacterium tuberculosis and Drug Susceptibility Testing on solid Medium.

[15] Treuer R, Haydel SE. Acid-fast staining and PetroffHausser chamber counting of mycobacterial cells in liquid suspension. Curr Protoc Microbiol 2011; Chapter 10: Unit 10A. 6. doi:10.1002/9780471729259.mc10a06s20.

[16] Willey JM, Sherwood LM, Woolverton CJ. Microbial growth. In: Willey JM, Sherwood LM, Woolverton CJ, eds. Prescott, Harley and Klein's Microbiology. $7^{\text {th }}$ edn. New York, USA: The McGraw-Hill Companies, Inc. 2008: p. 11947. 
[17] Widdel F. Theory and Measurement of Bacterial Growth. (04 May, 2007/ corrected version: 05 June, 2010) (www.mpibremen.de/ Verschiedenes/ Skripte und Universitäres).

[18] Katoch VM, Kumar TM. Nontuberculous mycobacterial infections. In: Sharma SK, Mohan A, eds. Tuberculosis. $2^{\text {nd }}$ edn. New Delhi, India: Jaypee Brothers Medical Publishers (P) Ltd., 2009: p. 667.

[19] Shanker SV, Jain NK, Chandrasekhar S, et al. Prevalence of atypical mycobacteria in sputum of patients undergoing treatment at a tuberculosis clinic. Indian J Chest Dis Allied Sci 1989;31(1):9-13.

[20] Chakrabarti A, Sharma M, Dubey ML. Isolation rates of different mycobacterial species from Chandigarh (North India). Indian J Med Res 1990;91:111-4.

[21] Jesudason MV, Gladstone P. Non tuberculous mycobacteria isolated from clinical specimens at a tertiary care hospital in South India. Indian J Med Microbiol 2005;23(3):172-5.

[22] Karak K, Bhattacharyya S, Majumdar S, et al. Pulmonary infection caused by Mycobacteria other than $M$. Tuberculosis in and around Calcutta. Indian J Pathol Microbiol 1996;39(2):131-4.

[23] Simons S, Van Ingen J, Hsueh PR, et al. Non-tuberculous mycobacteria in respiratory tract infections, eastern Asia. Emerg Infect Dis 2011;17(3):343-9.
[24] Central TB Division, Directorate General of Health Services, Ministry of Health \& Family Welfare, Revised National Tuberculosis Control Programme, DOTS-Plus Guidelines. January 2010: p. 1-5.

[25] Ramachandran R, Nalini S, Chandrasekar V, et al. Surveillance of drug-resistant tuberculosis in the state of Gujarat, India. Int J Tuberc Lung Dis 2009;13(9):1154-60.

[26] Santha T, Thomas A, Chandrasekaran V, et al. Initial drug susceptibility profile of M. Tuberculosis among patients under TB programme in South India. Int J Tuberc Lung Dis 2006;10(1):52-7.

[27] Paramasivan CN, Venkataraman P, Chandrasekaran V, et al. Surveillance of drug resistance in tuberculosis in two districts of South India. Int J Tuberc Lung Dis 2002;6(6):479-84.

[28] Rahman M, Kamal SMM, Mohammed FR, et al. Antituberculosis drug resistance pattern among different category of tuberculosis patients. J Medicine 2009;10(2):45-7.

[29] Jain NK, Avashia S, Bajpai A. Drug susceptibility profile of M. Tuberculosis among category - ii failure patients under RNTCP drug susceptibility of $M$. Tuberculosis. SAARCTB 2011;8(2):6-10.

[30] Osman E, Daniel O, Ogiri S, et al. Resistance of Mycobacterium tuberculosis to first and second line anti tuberculosis drugs in South West, Nigeria. J Pulmon Resp Med 2012;S6(1):001. doi:10.4172/2161-105X.S6-001. 